\title{
What Makes Teaching an Effective Teaching? - A Conceptual Study on Academic Environment
}

\author{
Gurendra Nath Bhardwaj and Shrey Kumar
}

\begin{abstract}
Teaching is a learning exercise for both (teacher and taught), which has its own long life. The outcome of effective teaching is shared by all the beneficiaries of the society. Since teaching is a dynamic process, therefore, to obtain the level of effective teaching all the parties including teacher and taught need to work continuously for the common orientation. The present study will examine the different parameters which contribute in effective teaching. Parameters will be set based on the review of literature. The results will be cover the three dimensions like, from the view point of students, teachers, and industry person who give employment to the students. The study focuses on technical education, therefore it assumes that majority of the students study for getting placements, however, students can study for gaining knowledge to acquire higher education, clearing competitive examinations and for other purposes like starting their own venture in future.
\end{abstract}

Index Terms-Academic clinic, academic crime, academic hygiene, academic leakage, assessment error.

\section{INTRODUCTION}

As per many previous studies, students are influenced positively or negatively more from teachers in comparison to the subject. During elective courses selection process, students first ask about the teacher of the course. They also realize the fact that the same course taught by different instructor has different learning impact on their mind set, even if the market value of the course remains the same. In case of offline educational process where class interactions play an important role which keep students and teacher connected not only till the end of course but also for longer time. Therefore, in most of educational institutions, the teacher's academic performance is assessed more on their effectiveness of teaching elective courses apart from basic compulsory courses. These elective courses demand more attention of course in-charges.

This service has double blind impacts; quality education not only enriches the students but also the teachers as well. A teacher also compares the degree of their teaching effectiveness in same course batch-wise and year-wise. It helps a teacher to improve the course delivery for the next semester/term etc. Sometimes, effective teaching in one course motivates a course instructor to teach in more and application innovative way to teaching pedagogy and teaching style.

Manuscript received October 16, 2015; revised December 22, 2015.

The authors are with the NIIT University, Neemrana, RJ 301705, India (e-mail: gurendrabhardwaj@gmail.com, shrey.kumar@st.niituniversity.in).

\section{A. Effective Teaching}

Effective teaching does not mean only delivery of the lecture. The process of effective teaching also involves at least two learners like teacher and student. Since it's a process of mutual consensus and communication between teacher and students, therefore, it requires all the essential features of effective communication. Interestingly, at the same time it requires frequency matching of teacher and students which is influenced by several environmental factors. Class delivery is only one of the essential features of effective teaching; however, effective teaching cannot be completed without conducting class room teaching.

\section{B. Assessment Error}

Many of times a faculty fails to assess the students, which can be intentionally or unintentionally. The main reason for deliberately failing to assess the students is to save time and energy, so when the faculty decides the assessment criteria, they will prefer the least time consuming methods without caring about its impact. Asking Multiple Choice Questions (MCQs) and group assignments are designed not for fair assessment and learning objectives, they are just to save the time and efforts of the faculty as well as of the students. Both are happy at the cost of academic learning. There is also check and balance for the same.

\section{Academic Crime}

It has been observed that when the faculty members frequently cancel or reschedule classes on their own convenience or other engagements at a very short notice. It becomes an accident for the students who is consistently following the session plan and coming with the prior preparation in every class. At the same time it shows casual attitude of faculty member and promotes tardiness in the class about teaching/learning process. This discontinuity and ad-hoc planning of session significantly disturbs the flow of learning in class, lab etc. Some faculty members create a group of students for their routine work (like marking attendance, preparing assignments for the class, even designing questions and evaluations support). This attract small errors and shows careless attitude of a teacher about the teaching-learning process. These kind of unfair practices create distrust amongst the teachers and the taught, and creates negative environment in the class and losses the credibility of the faculty to maintain fair and transparent system of academic process in the course.

Another trend that has been observed, faculty members create groups on social networking sites like facebook and whatsapp. Interestingly, this mode of communication is used not for knowledge sharing and academic discussion but 
frequently used to update the class scheduling. Some teachers even take the opinion from students about scheduling and rescheduling the classes. In this situation, even a small number of casual and notorious students who are least interested in learning but are very active on social media become trend setters of the class, because many of the students avoid these kinds of acts. Sometimes, faculty also change evaluation components either for their convenience or to favor some of their favorite students if they could not perform well. There are many examples of such kind of unethical and unfair practices. All these activities are examples of academic crime.

\section{Academic Leakage}

Assessment error and awareness about the learner's learning style, academic crime creates significant and consistent leakage points in teaching learning process. Many of times, this academic leakage is not visible, hence not diagnosed at the right time. If it is discovered when some academic accident happens, higher authorities get trapped into unavoidable situations because of some skewed results declared by the faculty members. In large group of students, if majority of students are weighing on an extreme side of evaluation grades, it is an alarming situation for the authorities. It gives an opportunity for the students to crib about the faculty members, teaching-learning process and create bad image about the institutions. This kind of academic leakage has long term impact and consumes a lot of time/energy of the responsible stakeholders for damage control.

\section{REVIEW OF LITERATURE}

Doctoral program fails to bring effective teachers due to lack of Pedagogical Content Knowledge (PCK) [1]. Research oriented doctoral program avoid important aspects of effective teaching like preparation for teaching, curricular planning, collegiality and services. PCK mainly includes subject matter knowledge which influences pedagogical contents knowledge including curricular knowledge, instructional strategies and knowledge of assessments and teacher understands. The study has very carefully examined the growth of a doctoral student and proposes the phase-wise development of a doctoral student into a teacher then finally as a mentor through PCK. It explains with two variables at learner's rate and professional continuum, however, some doctoral programs include learning of teaching methods.

Lot of challenges faced by the teacher while addressing young students [2]. Most of the time students confront to the teacher due to physical, social, emotional and cognitive changes. Due to different culture, region and race, some of the cultural conflicts were also noticed. The best practices in effective teaching include case study teaching, real life experience of diversified students, cooperative learning, doer language printed material, field trips, guest speakers, inviting parents to campus and class, peer learning, role playing, etc. This group also prefers to learn through hands-on learning experiment.

Students are end users of the education system. Ref. [3] Focus on student's perception about effective teaching. The analysis done on the primary data collected from 17000 students including on-campus and off-campus, through 40 questions based questionnaire. Mainly 9 characteristics were found effective in the study conducted at Memorial University which includes respectful, knowledgeable, approachable, engaging, communicative, organized, responsive, professional and humorous. The student would perform better for a teacher who shows an emotional investment in their academic achievement. Teacher who can be trusted makes student more eager to learn and more comfortable in a classroom environment. It was observed that there is a strong correlation between instructor's interest in that course and student's success. Courses taught by teaching assistant, show that professor and university is not valuing students.

The study [4] discusses about the methods of effective teaching in undergraduate engineering. The faculty must know the learning style of the students for effective teaching. Due to the changing needs of employers, students, and wider political and economic changes; problem based learning (PBL) was getting leverage over traditional teaching-learning process. In engineering education, faculties have complaints about the students that they fail to learn from the material presented before them and even score well without having conceptual knowledge. Student who has deep knowledge approach leads to enjoyable and satisfactory learning environment to improve their academic performance with their active involvement. Assessment focuses on evaluating understanding than memorizing and reproducing.

There is an impact of teacher's perception, thinking, sense of control, on their teaching [5]. The study brings four main attributes of a teacher for being an effective teacher: Survival; Reliance; Persistence and Innovativeness. Through self-efficacy, teacher makes difference in the life of a student as per their own belief. The study discusses five assumptions for effective teaching like Self-Reflection, Intentional Behavior, Symbolic Representation, Self-Regulation, and Triadic Reciprocal Caution. The teacher must have cognitive capacity to self-reflect, self-motivate, and self-regulate to harness the self-efficacy to control their thinking, behavior and emotions.

Five important factors of effective teaching like Teacher's knowledge; enthusiasm and responsibility for learning; classroom learning to encourage learning environment; assessment that encourages learning; effective feedback that establishes the learning process in the class and effective interaction between the teacher and the student for creating an environment that respects, encourages and stimulates through experiences [6]. The moment teacher gets passionately involved in teaching-learning process, they take a step forward towards effective teaching and create a learning environment for the students.

The best practices adopted by great teachers in the teaching career [7]. Expert teachers differ from their colleagues as these expert teachers are very highly rated by their students. These teachers take the responsibility of student's outcome and treat students as an individual and not as a crowd. It is visible by the fact that effective teachers enjoy their teaching and not treat that as a burden. In university teaching, there is also a prospective difference between teacher and student about rating the effective teaching. 
There are evidences of insight about positive impact of effective teaching on student's achievement [8]. It establishes the mixed linear relationship of time, race, teacher's effectiveness, gender, impact of teacher's effectiveness in last 3 years on the student's score. Effective teaching also reduces the overall achievement gaps. The poor performance of the student in the assessment may be because of ineffective teaching in the course. Teaching effectiveness can be improved through sustained collaborative and professional development. Since study is based on science teaching in USA, so it also compares various aspects of science teaching like effective science instructions and impact of teacher's effectiveness on the student's achievements. The data has been collected from classroom observation through local systematic change classroom observation protocol (LSCCOP) and scanned on discovery inquiry test (DIT). Even in a heterogeneous group of students; students taught by effective teachers perform better than their peers.

A senior professor, expressed concern as to why are effective teaching tools not adopted [9]. Lack of self-discipline among the teachers forces them not to do practice and hard-work in their teaching which ultimately decreases their interest and the level of confidence in the class. Competition is avoided in academics; even the students don't wish to share their score in public, whereas in sports, the results are declared in public to show the fare competition among the players. Effective teachers are punished because higher scores awarded by them also creates problem for parents and institutions. The achievements of athletic is accounted and rewarded if the athlete wins the game and on the other hand academic teaching is not awarded even if the student gets anything good in his life due to the academic input and learning from the teacher. Therefore, effective games coaches attract more parents and students than effective academic teacher. Effective teachers are also moving from academic to industry as they realized that there are good opportunities to work in the industry. Their effectiveness is more demanded in industry as people are quality conscious in the industry in comparison to academics.

For many teachers there are challenges of teaching in a heterogeneous classroom [10]. Fear of parents, student's perception, obstacles in understanding various languages, global immigration trends and student's living issues are very common challenges along-with financial and economic issues of learners. Parents were also found to be an influential factor to impact the effective teaching negatively. Effective teacher identifies the individual strength, learning needs, skills and talents of the students. He also modifies and adjust the curriculum, assessment criteria's to accommodate all possible variables which help in improving learning and motivation of the students. Equitable classroom by identifying different intellectual abilities and competencies create an environment for effective learning. The teacher needs to work towards balanced interaction among weak and good students to ensure equal distribution of the knowledge.

The student's evaluation about the teacher is quite an important input to improve teaching skills [11]. Out of 30 factors, 9 factors were found dominating in the survey of 50000 classes representing 1 million responses. Providing weightage to various influencing factors are also challenging and debatable issues and may vary situation to situation. Student's evaluation is considered as "puree" rather than apple and orange to make it effective teaching. Multidimensional approach provides sophisticated and realistic assessment of various factors of effective teaching.

Student's Evaluation of Teaching (SET) which is multi-dimensional, reliable, stable, and exclusively related to the instructor and not to the course and relatively valid against variety of the parameters of effective teaching [12]. No single criterion can be defined as sufficient tool to assess the effective teaching. The purpose of SET is to improve teaching quality by diagnosing the faculty feedback, information about the selection of course by the students. Interestingly, conflicts were found in the study like, students vs alumni rating, teaching vs course effects, students learning in multi-section classes, etc. Evaluation of effective teaching can be performed by self-assessment, peer's evaluation, external observer rating, multiple evaluations with different prospective, etc. Research productivity-teaching and research nexus, potential biasness in the student's evaluation were found to be debatable factors.

Some successful classroom strategies are adopted by teachers for effective teaching and showing effectiveness in maximizing the achievement of the student [13]. Problem Based Learning (PBL) focuses on student centered teaching approach. It demands student's active involvement in the learning process and subject matter as authentic, interesting and relevant as prerequisite. The role of teacher needs to be as a facilitator of a learner than as a director, to provide an opportunity to individual learner to acquire knowledge, reflection and sharing of ideas with others. The study compares attributes related to stronger and weaker influences on student's learning involvement. Teacher's feedback on student's performance has highest effect size (1.13) and retention has lowest effect size $(-0.15)$ as a weakest influence. It also captures sources of their attributes which are mainly teacher, student, home, school and peers for effective teaching and learning provision, teaching standard and ongoing teacher professional development.

The study [14] explains six principles of effective teaching like Commit to teaching under-prepared students; Demonstrate good command of the subject matter; Ability to teach a diversified student population; Address non-cognitive issues that effects' learning, provide open and responsive learning environment; Communicate high standards and engage in on-going evaluation; and Professional development. Higher education institutions must recognize the impact of effective teaching to enhance the learning skills of all types of the students. Due to the lack of effective teachers, many of the teachers cannot use their full potential which is also a national loss.

Mapping of higher education projects is also an important element for effective teaching [15]. The study is based on conducting collaborative research in higher education. To improve togetherness, harmony and belongingness, joint meal and social engagements were arranged for the faculty members who are involved in the collaborative research. It was also observed that student feedback is important only in active environment not in a passive environment. Collaborative research provides an understanding of teaching 
and learning commitment with values and professionalism. It also constructs learning communities which facilitate the collaborative research. However, in group projects, students confessed during the survey that they cheated each other without learning anything and accepted that cheating was enjoyable.

Parent's role in student's development is quite important [16]. The study identifies four core parenting dimensions like Control, Maturity demand, Democratic communication and Nurturance. 452 teachers from middle school were assessed based on the parenting dimensions. High expectation was most positive attribute and negative feedback or lack of nurturance was found most inconsistent attribute. Student's motivation was studied in reference to teacher's ability of care-giving. The study also found a relationship between parent socialization and student's school related adjustments. Student's involvement was assessed with 10 item school motivation scale including classroom behavior, control belief; academic performance and teaching dimensions were assessed to examine the quality of effective parenting. However, teaching style of a teacher appeared as school related outcome.

To make effective teaching and effective teachers, the study has identified common factors like the provision of opportunity to learn, class room organization, task setting, task contents, teaching skills, teacher student interaction etc. Based on the sample of 71 primary teachers out of 228 primary teachers, effective and ineffective teachers were classified, their performance were validated. Task presentation and lesson structure also makes a sense in effective teaching [17].

It was felt to examine the student's view on effective teaching in higher education [18]. 7 variables were observed as the key drivers of effective teaching, like adopting the student's need, using meaningful examples, motivating students to do their best, facilitating the course effectively, delivering a valuable course, communicating effectively and showing concern about student's learning. These variables collectively contributed approx. $86.2 \%$ in effective teaching. Effective teaching brings out active participation of the students in learning, working hard trust-worthy relationship, and provide structured yet flexible classroom environment. Prior preparation of course design, session plan, assessment criteria, and declaration of discussion topics make the effective teaching on a greater degree.

\section{PROPOSED MODEL}

Based on the review of literature, past experiences and focused group interviews with students, parents and non-teaching staffs, we propose the following key characteristics to be maintained and adopted by the faculty members to make effective teaching.

\section{A. Academic Hygiene}

When we eat food, we feel very conscious about the hygiene starting from cooking till the service of the food, because we know the impact of unhygienic food on our health. In the same manner, in today's technological world, when students feel that the material presented by the faculty member for their learning will affect the academic health negatively, they try to avoid reading the contents for whatever reasons. The plagiarism of the material, uselessness, unorganized presentation, and irrelevant academic material etc. create unhygienic academic environments. An effective teacher must ensure the academic hygiene.

\section{B. Consumer vs Customers}

Hot and quite debatable issue among many of the private educational institutions is that students are customers or not? They are not customers for sure. But they are consumer of academic output (which a faculty member produces by various methods of teaching). The quality of academic service can be improved if the teacher is well aware about the individual learning style, skills, and talents of their students.

\section{Know Your Students (KYS)}

Many of the financial institutions and other service companies apply this concept, before providing the service to the customer; the service provider must know the relevant information about their end-users of the services. This not only helps the service provider in providing better service but also better planning. The essence of this concept is that the degree of effectiveness in teaching is based on this concept that how much a teacher knows about his students. A teacher tries hard to explain the concepts as a sender of communication and fails to communicate to the receiver with same quantity and quality; we term it as transmission loss. By adopting the concept of KYS, this transmission loss can be minimized up to great extent.

\section{From Teacher to Facilitator}

Another issue of conflict in higher education is about teacher or knowledge faciltor? What is the exact role ought to be? Many effective teachers got the teaching effectiveness in their career, when they created a learning environment where a learner can learn on their own and the teacher has extended all support which is required to every indvidual learner. In this connection, a teacher must plan the course and efficient teaching learning process to ensure implemention of following stepts properly.

Teaching in a class is individual show for every teacher, which has no repeat telecast in their whole life with same audience at same level of learning frequency. When a teacher treats their class as one time life changing event, they contribute $100 \%$ efforts to make it a success. Therefore, prior a class, an effective teacher should anticipate all good or bad incidents which may take place during the class and mentally prepare himself for the same. This mental preparation gives a different kind of confidence to a teacher which is also refleected by their body language when they interact with the students in the class.

In the context of above, there are few prerequisites for a teacher to deliver quality education. This can be divided in following segments. Ref. [19], Pre Course Preparation, In Class Participation and Post Class Engagement. Therefore, it demands a scenario, where a Course in Charge has to ensure efficiency in three main steps of academic administration processes like Efficient Teaching Plan as mentioned in Fig. 1. It has cyclical impact, hence all steps should be planned properly to get desired academic results. 
To engage the whole class of $60+$ students is another challenge for many faculty members, therefore the teaching pedogogy must have balance and mixed teaching styles and appropriate usage of audio-video tools. The active sense of curiosity brings the student in the next class.

After class engagement, students require well planned home assignments, timely feedback and higly connected learning environment where students and teacher interact freely $24 \times 7$. The information technology and advance gadgets play a vital role. Sometimes, effective teaching in one course motivates a course instructor to teach more and do more innovation in the teaching pedagogy and teaching style.

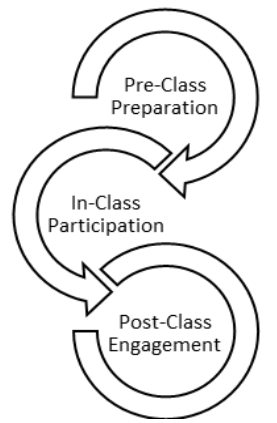

Fig. 1. Efficient teaching plan.

\section{E. Academic Clinic}

Now, the whole process of polluted academic process creates a set of students who were good at the time of their admission in the institution, but now they are not performing up to the mark. These kinds of situations create a demand of academic clinic. Many of the students from very good background become victim of the wrong academic practices, and are also treated as liabilities by the institution, which is a very common error done by the institutions including faculty. The students either go into depression or indulge themselves into bad habits which include consumption of toxic contents and drugs. They are also treated badly by the family, friends, faculty members, society and other concerned. But unfortunately, close monitoring worsens the situation. It is also an ill treatment of depressed mental situation. This population does not need any monitoring, they need intensive mentoring. Many of the people are not able to make difference between monitoring and mentoring (including parents). The concept of academic clinic is blended with a group of highly motivated students, sincere and matured faculty members and aware parents working together for mission to revolutionize the mind through high spiritual quotient. The gradual doses of spirituality rehabilitate the students during short period of time if they are handled by the team of experts. Due to specialization and expertise, team members handle them sensitively, because the team treats them as patient not as criminals. They try bringing mental stability in the mind of the academic patient, and achieving the level of awareness that they can judge what is right or wrong, and then take decision accordingly. It all happens only with the consent of the concerned students through short term courses of yoga, pranayam, social work and positive gathering and knowledge sharing group (satsang). The concept of academic clinic brings customized package of mental treatment for these academically disconnected students. Different students require different doses of care to bring them at a comfortable level and to develop sense of love with studies rather than fear. As mentioned in Fig. 2, Academic Rehabilitation Process establishes the cause and effect relationship among all the elements like Academic Crime, Academic Leakage and Academic Clinic.

This paradigm shift in students' attitude, make them aware about themselves and present environment. They are able to see the same world with different lenses and feel better about the same teacher, subject and other components of learning environments. Though it's a long process of rehabilitation but, even small success gives lot of satisfaction and motivation to teacher, learner and other contributors to accept the positive changes.

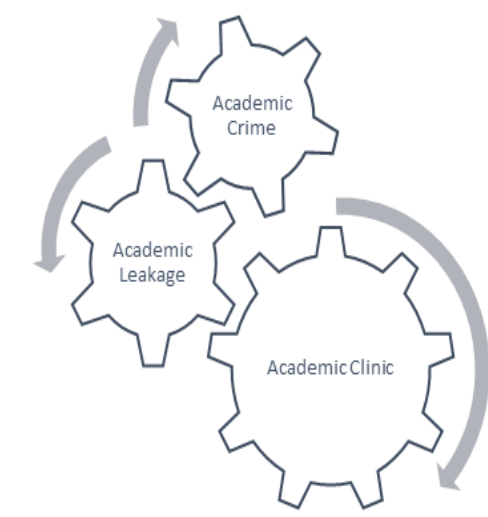

Fig. 2. Academic rehabilitation process.

\section{CONCLUSION}

Effective teaching is demanded at all levels of education. As the hierarchy of education increases, its gravity increases. Every stakeholders of any education system recognizes the impact of its absence. There may be difference of opinion on the degree of effectiveness, but undoubtedly it is required in all kinds of teaching and learning processes. All of us accept benefits of effective teaching, but hesitate to change the present system of teaching learning process. In many of premier B schools and engineering colleges, students drop the college because their hidden talents are not duly scrutinized at the entry time during selection process.

Another aspect of the effective teaching is the institutional support by providing positive environment and reasonable teaching feedback for correction in teaching pedagogy, style, contents and other aspects. Teaching feedback should be taken from academically sound students and based on rating, teacher must be asked about the plan for academically poor students, accidently, in many institutions it happened the other way round.

\section{REFERENCES}

[1] S. K. Abell, M. A. P. Rogers, D. L. Hanuscin, M. H. Lee, and M. J Gagnon, "Preparing the next generation of science teacher educators: A model for developing PCK for teaching science teachers," Journal of Science Teacher Education, vol. 20, no. 1, pp. 77-93, 2009.

[2] B. N. Allison and M. L. Rehm, "Effective teaching strategies for middle school learners in multicultural, Multilingual classrooms," Middle School Journal, vol. 39, no. 2, pp. 12-18, 2007

[3] J. Delaney, A. Johnson, T. Johnson, and D. Treslan, Students' Perceptions of Effective Teaching in Higher Education, Board of Regents of the University of Wisconsin System, 2010. 
[4] A. K. Ditcher, "Effective and leaning in higher education with particular reference to undergraduate education of professional engineers," International Journal of Engineering Education, vol. 17, no. 1, pp. 24-29, pp. 1-14, 2001.

[5] C. Gibbs, "Explaining effective teaching: Self-efficacy and thought control of action," Journal of Educational Enquiry, vol. 4, no. 2, 2003

[6] P. Gurney, "Five factors for effective teaching," New Zealand Journal of Teachers' Work, vol. 4, no. 2, pp. 89-98, 2007.

[7] N. Hativa, R. Barak, and E. Simhi, "Exemplary university teachers: Knowledge and beliefs regarding effective teaching dimensions and strategies," Journal of Higher Education, vol. 72, no. 6, pp. 699-729, 2001.

[8] C. C. Johnson, J. B. Kahle, and J. D. Fargo, "Effective teaching results in increased science achievement for all students," Journal of Science Education, vol. 91, no. 3, pp. 371-383, 2006.

[9] O. R. Lindsley, "Why aren't effective teaching tools widely adopted?" Journal of Applied Behavior Analysis, vol. 25, no. 1, pp. 21-26, 1992

[10] R. Lotan, "Teaching teachers to build equitable classrooms," Theory into Practice, vol. 45, no. 1, pp. 32-39, 2006.

[11] H. W. Marsh and L. A. Roche, "Making students' evaluations of teaching effectiveness effective, The critical issues of validity, Bias, and utility," American Psychologist, vol. 52, no. 11, pp. 1187-1197, 1997.

[12] H. W. Marsh, "Students' evaluations of university teaching: Research findings, methodological issues, and directions for future research," International Journal of Educational Research, vol. 11, no. 3, pp. 253-387, 1987.

[13] K. Rowe, "Effective teaching practices for students with and without learning difficulties: Issues and implications surrounding key findings and recommendations from the National Inquiry into the teaching of literacy," Australian Journal of Learning Disabilities, vol. 11, no. 3, pp. 99-115, 2006.

[14] P. Smittle, "Principles for effective teaching," Journal of Developmental Education, vol. 26, no. 3, 2003.

[15] M. Walker, Reconstructing Professionalism in University Teaching Teachers and Learners in Action, Open University Press, 2001.
[16] K. R. Wentzel, "Are effective teachers like good parents? Teaching styles and student adjustment in early adolescence," Child Development, vol. 73, no. 1, pp. 287-301, 2002.

[17] D. Wray, J. Medwell, R. Fox, and L. Poulson, "The teaching practices of effective teachers of literacy," Educational Review, vol. 52, no. 1, pp. 75-84, 2000.

[18] S. Young, "Student views of effective online teaching in higher education," American Journal of Distance Education, vol. 20, no. 2 , pp. 65-77, 2006

[19] S. Kumar and G. N. Bhardwaj, "Effective teaching and learning process through project based learning (PBL)," presented at the 3rd 2015 IEEE International Conference on MOOCs, Innovation and Technology in Education, ACET, Amritsar, Punjab, India, Oct. 1-2, 2015

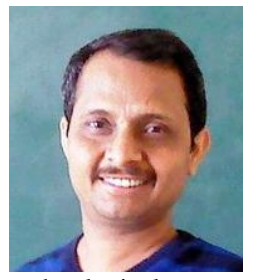

Gurendra Nath Bhardwaj was born in Etawah (UP), India, in 1974. He pursued his M.Com. (1997) and Ph.D. in applied economics in 2003 from University of Lucknow. Presently he is an associate professor and the deputy registrar (academic operations) at NIIT University, Neemrana (RJ), India. His research areas are mainly applied economics, financial markets, financial services, banking, and technological aspects in economics etc.

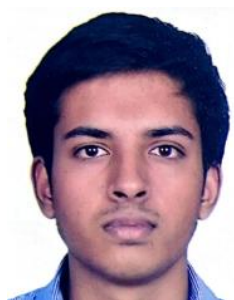

Shrey Kumar was born in Ghaziabad (UP) India, in 1995. He completed his High School and Senior Secondary School from Ryan International School, Gurgaon (HR) in 2013. He is pursuing B.Tech/B.E. in electronics and communication engineering (2013-17). Presently he is working as a research associate with Dr. Gurendra Nath Bhardwaj at NIIT University. His research areas are mainly electronics, communication, power, energy efficiency and general aspects of finance and economics. 